\title{
Low-Resolution and Low-Cost Position Sensor Implementation for Permanent Magnet Synchronous Motor Driver
}

\author{
Mehmet Cihat Ozgenel ${ }^{1}$, Gungor Bal ${ }^{2}$, Durmus Uygun ${ }^{3}$ \\ ${ }^{1}$ Department of Electrical and Electronics Engineering, Engineering Faculty, \\ Erzincan University, \\ 24030, Erzincan, Turkey \\ ${ }^{2}$ Department of Electrical and Electronics Engineering, Faculty of Technology, \\ Gazi University, \\ Teknikokullar, Besevler 06590, Ankara, Turkey \\ ${ }^{3}$ Department of Electrical and Electronics Engineering, Faculty of Engineering and Architecture, \\ Gediz University, \\ 35665, Izmir, Turkey \\ durmus.uygun@gediz.edu.tr
}

\begin{abstract}
Permanent magnet synchronous motors (PMSM) are recently getting involved in many usage areas such as industrial, robotic, home and office applications due to the fact that they have several advantages like fast dynamic response, low size, high efficiency, high power density and more reliability. Since PMSMs require rotor position information for phase current commutation, a position encoder is used on the rotor. Unfortunately, position sensor increases the size and cost of the driver system. In this study, a simple low cost position sensor based on photomicrosensor is proposed to replace the position encoder. A driver system for 12 poles PMSM with developed position sensor was set up and tested under different speed and load conditions. The experimental results proved that the PMSM driver is able to deliver sinusoidal currents to stator phase windings along with demonstrating the effectiveness of the proposed sensor.
\end{abstract}

Index Terms-PMSM driver; phase current commutation; low cost position sensor; photomicrosensors.

\section{INTRODUCTION}

Permanent magnet brushless motors need rotor position information for commutation. In BLDC motors the position sensors are usually three hall-effect sensors, in PMSM's the position sensors are encoder or resolver. According to information from position sensors, the driver switches inverter transistors in order that appropriate current is applied to the stator windings of the motor. When position sensors are used in the drive system, its size and cost increases. So, sensorless drive has been a new subject of study and researchers have focused on sensorless drives. The last thirty years, a great number of studies have been presented about sensorless drive systems [1]. But, there has still been lack of the sensorless drive systems where high starting torque and accurate torque control requirements at low speed [2]. In addition, sensorless control needs more complex control algorithms and more complicated circuitry

Manuscript received 29 October, 2015; accepted 3 March, 2016
[3]. In sensorless drive system, there are also some difficulties about sensing initial rotor position from rest position of rotor and at low speeds [4]. These deficiencies have restricted to be applied the sensorless drive system to use in many home, industrial, robotic and aerospace applications [1].

There are also many studies using sensor on the brushless motor drive system but using low cost and low resolution position sensor. Applying low cost and low resolution position sensor to brushless driver was introduced by Corzine and Sudhoff in 1996 [5]. In the same year, Morimoto et al. introduced a similar study [4]. Corzine and Sudhoff used a hybrid observer to obtain actual velocity for speed control block and to obtain cos and sin values for reference frame transformation block in order torque control. The input of the hybrid observer depends on the three of two active Hall-Effect sensors so changing the state of Hall-Effect any two sensors restricted the error in the extrapolated transformation expression. The study of Morimoto et al. also based on the average speed, consisting of linear prediction in obtaining a position estimate. Other works are more advanced form of average velocity [6], [7]. F. G. Capponi et al. used average velocity which has limitations in as known the zeroth-order Taylor algorithm [8].

Using Hall-Effect sensors for obtaining high resolution rotor position there is usually two main methods. In the first method, the synchronous rotating frame that is used with measured phase voltages and currents to obtain rotor velocity, then position of rotor is attained [8], [9]. In the second method, to obtain more accurate rotor speed and position [10], [11] mechanic model is used to compensate load effect by the average velocity vector-tracking observer. The research in a rotor position observer uses three HallEffect sensor signals and current to obtain rotor position then vector control implemented. The methods described above concentrated on speed control for PMSM equipped 
with hall-effect sensor. All methods explained above have complex algorithm and a DSP should be used to carry out the complex algorithm.

This experimental work presents using a low resolution position sensor for PMSM which is driven with space vector modulation technique (SVPWM). In order to feed stator winding of PMSM with sinusoidal current, high resolution position sensor is needed. It is possible to implement a PMSM driver producing sinusoidal current without using high-resolution position sensor, which requires a DSP and complex algorithms [6]-[11]. Fortunately, with new developments regarding motor control, multifunctional integrated devices have been introduced by manufacturers. One of these integrated devices is FCM8201 from Fairchild Semiconductor. In this work, the FCM 8201 based driver with SVPWM technique and a low resolution position sensor has been manufactured for 12-poles PMSM.

\section{Design Details AND Algorithm of Proposed SYSTEM}

The setup of the proposed system consists of three parts. Low resolution and low cost position sensor, 12 poles PMSM and FCM8201 based inverter.

Low resolution and low cost position sensor: It is a plastic disc non passing IR light which is used to acquire rotor position. As shown in Fig. 1(a) 12-poles plastic disc manufactured has been mounted on the rotor shaft and three (Omron) photomicrosensors (transmissive) are used for sensing the rotor position [12] in this study. The rising and falling time of the photomicrosensors (transmissive) are typically $4 \mu \mathrm{s}$.

PMSM with 12-poles: 3-phase, 12-poles, interior permanent magnet rotor and ironless PMSM is used as a test motor. The motor parameters are given in Table I.

TABLE I. PMSM PARAMETERS.

\begin{tabular}{|c|c|}
\hline Parameter & Value \\
\hline Number of phases & 3 \\
\hline Number of poles & 12 \\
\hline Phase resistance & $4,1 \Omega$ \\
\hline Phase inductance & $1,16 \mathrm{mH}$ \\
\hline Rotor type & inner \\
\hline Back EMF constant & $0,05 \mathrm{Vs} / \mathrm{rad}$ \\
\hline Torque constant & $0,14 \mathrm{Nm} / \mathrm{A}$ \\
\hline
\end{tabular}

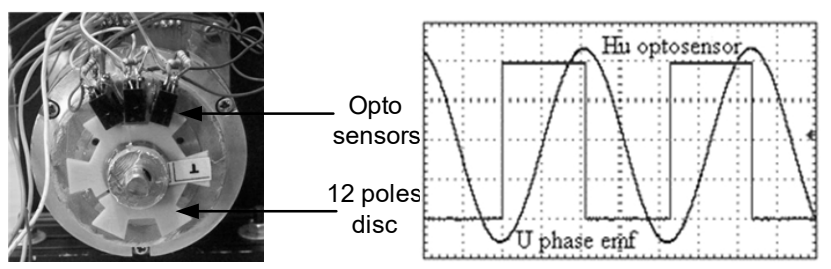

a)

b)

Fig. 1. Optic sensors and 12-pole disc (a); U-phase optosensor alignment with U-phase back EMF (b).

FCM8201 based inverter: FCM8201 is a device for controlling of three-phase PMSM or BLDC. It can be operated in a stand-alone mode or serial interface mode (SPI) with a microcontroller [13]. In this paper, the standalone mode is preferred without using any microprocessor. With using position signals from three low resolution position sensors, FCM8201 creates PWM signals in order to switch six inverter transistors. Besides, it has over current, voltage, heat protection functions.

Four hall-effect current sensors are used for observing three phase motor currents and dc link current on designed inverter system. The most significant part of experimental system is the alignment of optical sensors with related phases. In order to obtain the rotor position three photomicrosensors have been placed on the stator. And, PMSM is rotated by another motor and back electromotive forces are observed in order to insert the sensors in the right place. The falling edge of output signal from opto-sensor is aligned with upper half-cycle center of back EMF for Uphase as shown in Fig. 1(b) [13]. The similar procedure is performed for other phases.

As shown in Fig. 2 rotor speed is sensed by three optic position sensors which are placed on the stator out of 120 electrical degrees to each other. With three sensors, it is possible to get eight code combinations, but only valid six states are detected by optical position sensors. The remaining two codes $(000,111)$ are already invalid codes (Fig. 3). The six valid codes are used to generate phase reference voltages.

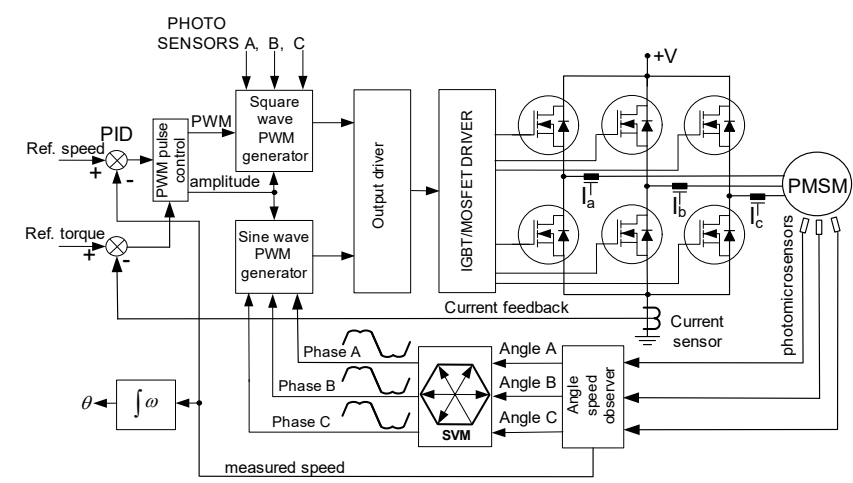

Fig. 2. Proposed system.

Position data from low cost position sensors are used to obtain reference for each phase for space vector modulation (SVM) and actual speed in each $60^{\circ}$ resolution. In SVM block, the reference signal for each phase is generated by using electrical $60^{\circ}$. Since the commutation occurs in every electrical $60^{\circ}$, generation of three phase signals using the SVM is more suitable as given in Table II which also gives the applied voltage levels versus phase winding related to the state of sensors.

In Table II the inverter transistors may be connected to $+\mathrm{V}_{\mathrm{DC}}$ or $-\mathrm{V}_{\mathrm{DC}}$ [14]. $\mathrm{A}, \mathrm{B}$ and $\mathrm{C}$ phase reference signals provide inputs for sine wave PWM generator block. In that case, phase reference signals are compared with $20 \mathrm{kHz}$ triangular waveform as referenced on Fig. 3 and then PWM for space vector signals are generated and following this operation, the SVPWM signals to drive the inverter transistors are transmitted to driver block output.

TABLE II. SPACE VECTOR INVERTER STATES.

\begin{tabular}{|c|c|c|c|c|c|c|}
\hline $\begin{array}{c}\text { Sensor } \\
\mathrm{C}\end{array}$ & $\begin{array}{c}\text { Sensor } \\
\text { B }\end{array}$ & $\begin{array}{c}\text { Sensor } \\
\text { A }\end{array}$ & $\mathbf{V}_{\mathrm{A}-\mathrm{B}}$ & $\mathbf{V}_{\text {B-C }}$ & $\mathbf{V}_{\mathrm{C}-\mathrm{A}}$ & Vector \\
\hline 0 & 0 & 0 & 0 & 0 & 0 & $\mathrm{~V}(000)$ invalid \\
\hline 0 & 0 & 1 & $\mathrm{~V}_{\mathrm{DC}}$ & 0 & $-V_{D C}$ & $\mathrm{~V}_{0}$ \\
\hline 0 & 1 & 1 & 0 & $\mathrm{~V}_{\mathrm{DC}}$ & $-V_{D C}$ & $\mathrm{~V}_{60}$ \\
\hline 0 & 1 & 0 & $-V_{D C}$ & $\mathrm{~V}_{\mathrm{DC}}$ & 0 & $\mathrm{~V}_{120}$ \\
\hline 1 & 1 & 0 & $-V_{D C}$ & 0 & $\mathrm{~V}_{\mathrm{DC}}$ & $\mathrm{V}_{180}$ \\
\hline 1 & 0 & 0 & 0 & $-V_{D C}$ & $\mathrm{~V}_{\mathrm{DC}}$ & $\mathrm{V}_{240}$ \\
\hline 1 & 0 & 1 & $\mathrm{~V}_{\mathrm{DC}}$ & $-\mathrm{V}_{\mathrm{DC}}$ & 0 & $\mathrm{~V}_{300}$ \\
\hline 1 & 1 & 1 & 0 & 0 & 0 & $\mathrm{~V}(111)$ \\
\hline
\end{tabular}




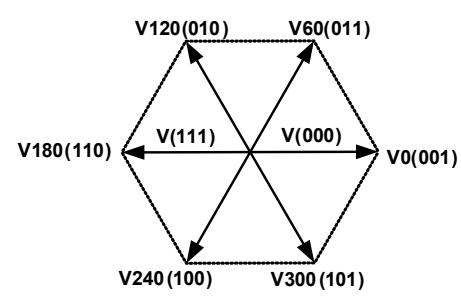

a)

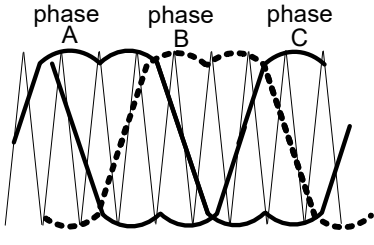

b)
Fig. 3. Space vector modulation states.

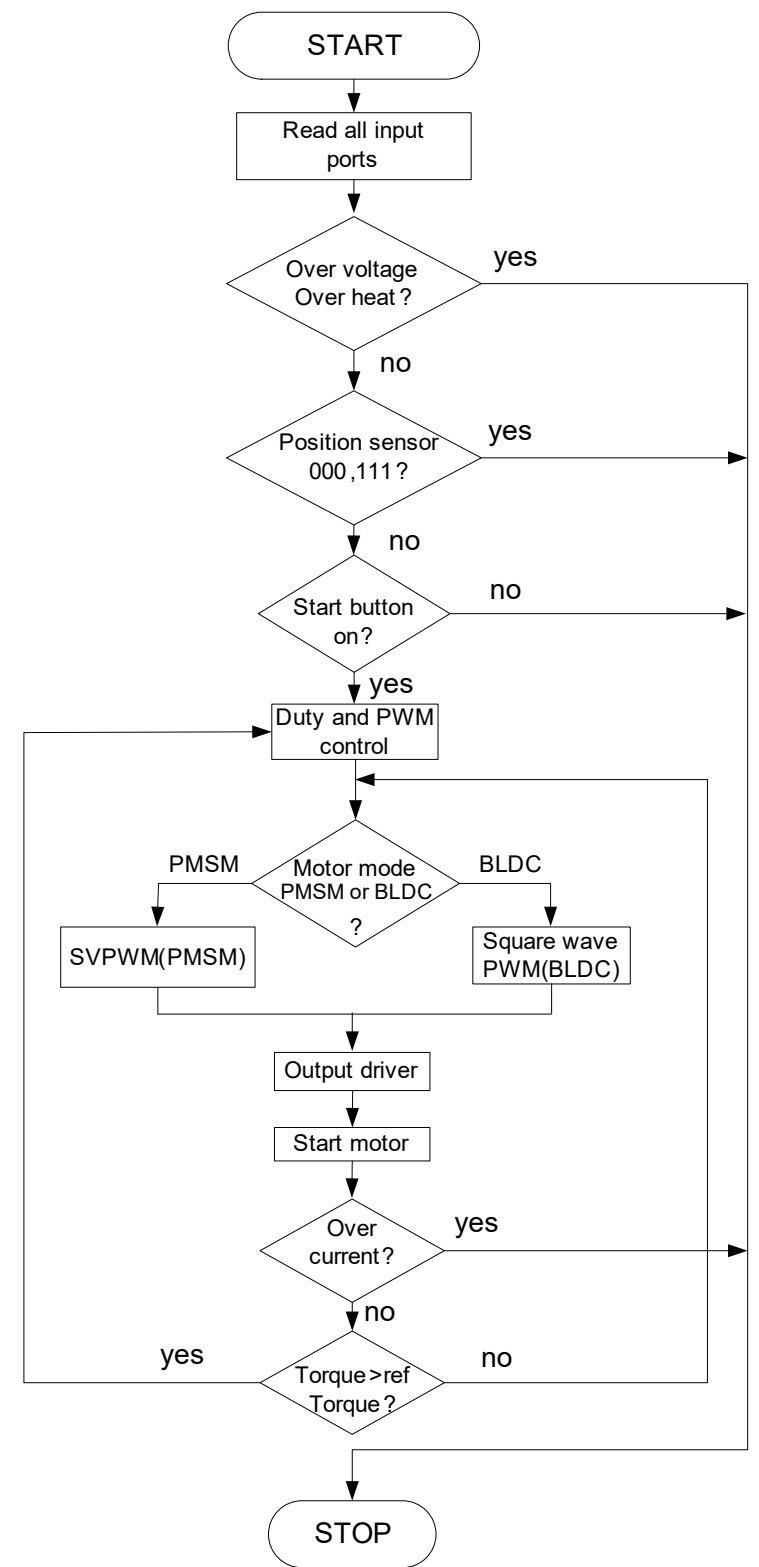

Fig. 4. The flowchart for the proposed system.

Measured speed from angle speed observer is compared with the speed reference signal in order to get the error signal. The error signal is applied to a PID controller to generate the amplitude of sine wave. Once deriving amplitude of sine wave, two variable parameters must be known. One is the period of sine wave which is obtained from one of three position sensors while the other parameter is phase advance. The amplitude signal from PWM pulse control block as seen on Fig. 3 determines motor current and torque. In PMSM mode, square wave PWM generator block is needed only on the first runtime. The PMSM starts as BLDC motor on the first runtime due to low resolution position sensors then shifts to PMSM mode. A Hall-effect current sensor on the DC link measures the dc link current to compare with the reference torque signal. After the DC link current is subtracted from the reference torque signal resulting error is applied to PWM pulse control block in order to update the required torque and speed signals. The hall-effect current sensors on A, B and C phases are used to observe the motor phase currents. The calculation of motor torque and output power is significant by using phase measured phase currents. The torque and power expressions of PMSM can be given by [15]:

$$
\begin{gathered}
T=\frac{1}{\omega}\left(e_{a} i_{a}+e_{b} i_{b}+e_{c} i_{c}\right), \\
P=T \omega
\end{gathered}
$$

where $T$ is electromagnetic torque in $\mathrm{Nm}, \omega$ is rotational speed in $\mathrm{rad} / \mathrm{sec}$ and $P$ is the power on the motor shaft. Besides, $e_{a}, e_{b}, e_{c}$ and $i_{a}, i_{b}, i_{c}$ are phase EMFs and currents respectively.

Figure 4 shows the algorithm of the proposed system. First of all, all system inputs are read. If there is over voltage or over heat in the motor and inverter, the motor is stopped. In the same way, the inverter stops in the case that a fault occurs in rotor position opto-sensors. Since brushless motors can operate as PMSM or BLDC motor, firstly operation mode is determined and then appropriate PWM signal is generated using data from position sensor. In this study the motor is operated in PMSM mode, so sinusoidal current is generated using rotor position data from low resolution and low cost position sensors. DC link current is measured with a hall-effect current sensor. When DC link current is higher than that reference current, motor is stopped. Likewise, generated torque and reference torque are compared. If the motor torque is higher than the reference torque the PWM is updated, otherwise the motor keeps on running in PMSM mode.

\section{EXPERIMENTAL STUDIES}

The experimental setup is shown in Fig. 5. PMSM was tested under various load and speed conditions.

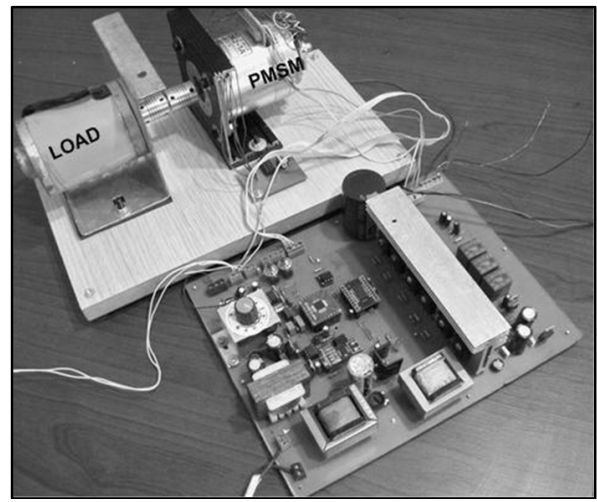

Fig. 5. Experimental setup.

In the experimental setup, PMSM was firstly rotated by another motor in order to know whether the back EMF signals of the motor were sinusoidal or trapezoidal. The EMF signals of the PMSM motor were fully sinusoidal as illustrated on Fig. 6.

In the first runtime, PMSM was operated under no load 
condition. Then, a load applied to the motor following the operation that the load was suddenly removed and the load was applied to the motor again while the motor was under load. Figure 7 shows DC link current $(0,7$ A) and speed (1124 rpm). As seen from Fig. 7, a small change in speed occurred in a very short time (1s/DIV) for the first runtime. When the load was removed, no change was observed on speed data. The speed was measured as $1124 \mathrm{rpm}$ and the load rate was 13.464 W. In Fig. 8, the case while PMSM was running with/without load was considered. For loading purposes, a permanent magnet DC generator (PMDCG) mechanically connected to PMSM shaft is used.

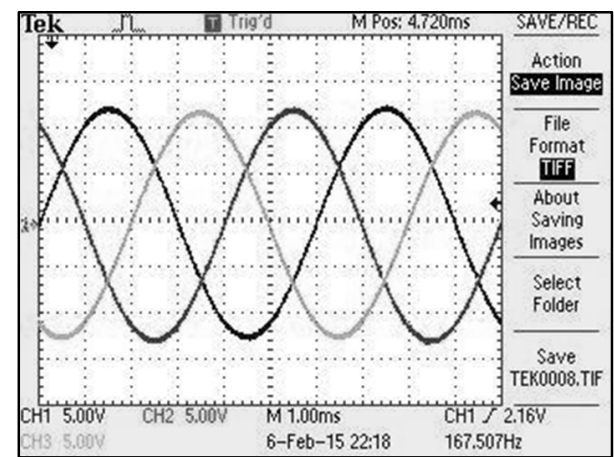

Fig. 6. Measured back EMF signals of PMSM.

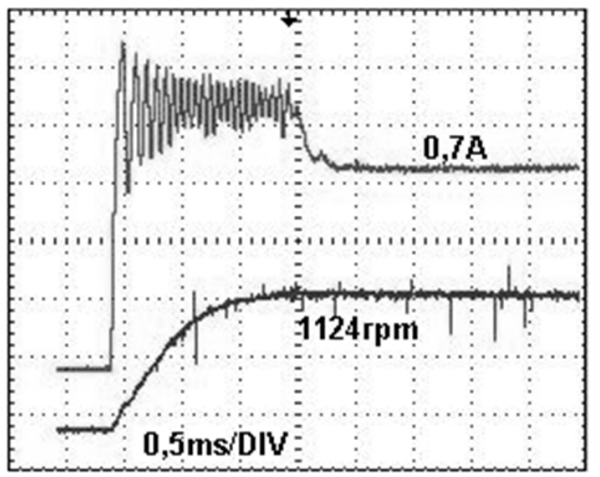

Fig. 7. DC link current and motor speed for motor startup in load condition.

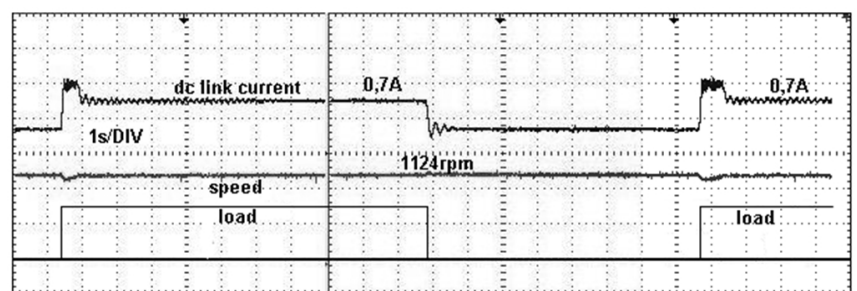

Fig. 8. PMSM speed and inverter current from DC source for unloaded and loaded cases.

Fig. 9 shows the signals for PMSM and inverter when the direction of PMSM was suddenly reversed at $1124 \mathrm{rpm}$ where this case is evidently indicated on Fig. 9(a). The PMSM tracked the new reference direction in $1 \mathrm{~s}$. It can be stated that DC link current was suddenly increased due to applied load and meanwhile, the speed response of the motor was quite effective since PID algorithm used in the system design had appropriate proportional, integral and derivative parameters.

In Fig. 9(b), the three-phase currents are shown when the motor is loaded. Although low resolution position sensors were used in driver system, the three-phase currents were sinusoidal. In Fig. 10, the motor is started as a BLDC in first runtime and then it shifts to PMSM mode.

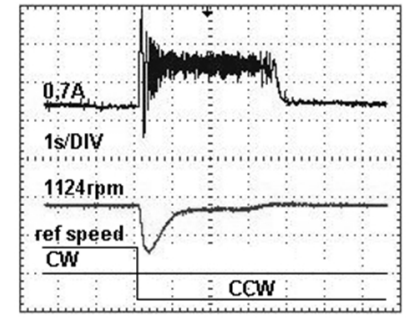

a)

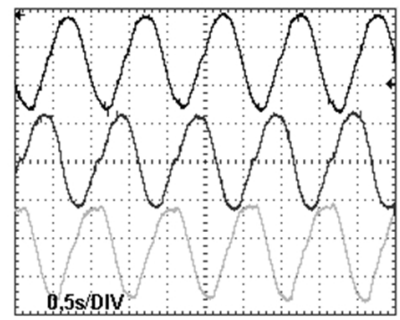

b)
Fig. 9. Current and speed responses to sudden changes in the speed direction (a); Phase currents under load (b).

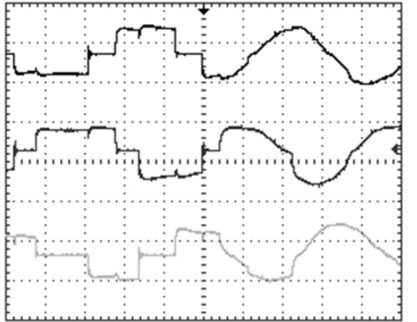

a)

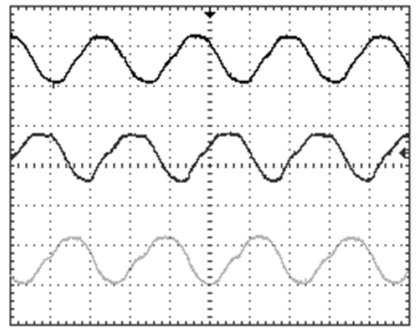

b)
Fig. 10. Motor runs as BLDC in first runtime (a); Motor phase currents at no load condition (b).

Figure 11 shows U-phase current, position sensor output and rotor position for $1000 \mathrm{rpm}$ in which motor speed can be found using (3)

$$
\operatorname{speed}(\mathrm{rpm})=\frac{\text { Position_sen_Freq } \times 60_{\text {poles } / 2} .}{\text {. }}
$$

As shown on Fig. 11, the frequency of the position sensor is $100 \mathrm{~Hz}(5 \mathrm{~ms} / \mathrm{DIV})$. Since motor has 12 poles the motor speed can be easily calculated as $1000 \mathrm{rpm}$.

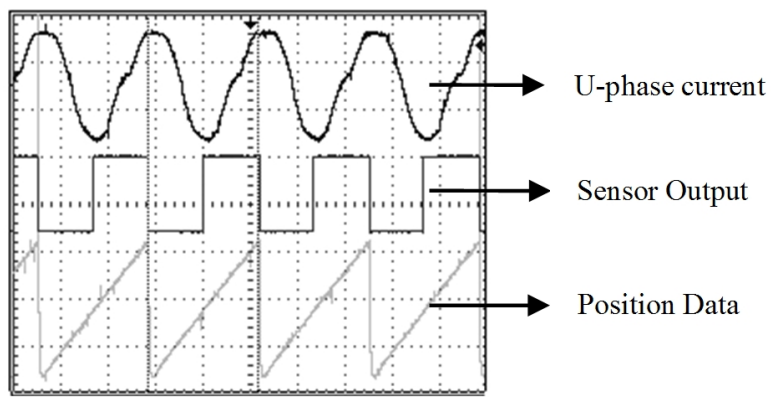

Fig. 11. U-phase current, sensor output and position.

In Fig. 12, while the PMSM was rotated by another motor at $850 \mathrm{rpm}$, U-phase back EMF was measured and recorded Fig. 12(a). Then, PMSM was operated under load with $850 \mathrm{rpm}$ and U-phase current was measured and recorded as in Fig. 12(b).

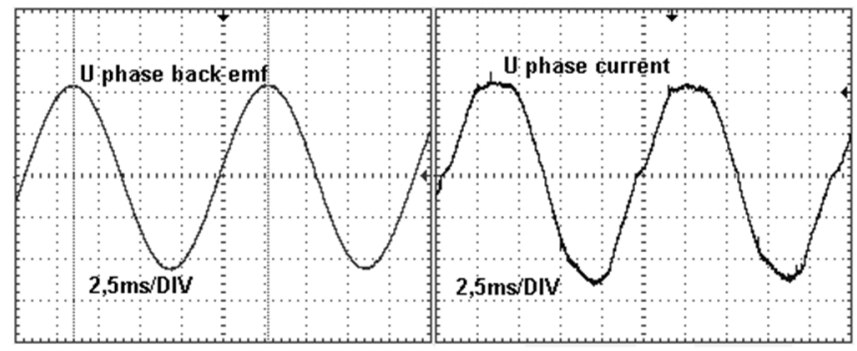

a)

b)

Fig. 12. PMSM rotating at 850 rpm: (a) Back EMF, (b) Phase current. 
U-phase current under load could be interpreted as quite close to U-phase back EMF which had sinusoidal waveform. When PMSM was rotating at $1124 \mathrm{rpm}$, the angular velocity $\omega$ was $117.64 \mathrm{rad} / \mathrm{s}$ and measured stator current was $0.816 \mathrm{~A}$ and back EMF was 5.5 V. Referring to (1) and (2), motor torque and shaft power could be calculated as $114 \mathrm{mNm}$ and $13.464 \mathrm{~W}$, respectively. When motor was rotated at 1124 $\mathrm{rpm}$, the frequency of the phase current was $112.4 \mathrm{~Hz}$.

\section{CONCLUSIONS}

In this study, a permanent magnet motor equipped with low resolution and low cost position sensor having sinusoidal back EMF is used. Experimental results are obtained for $1124 \mathrm{rpm}$ and $850 \mathrm{rpm}$ speed rates and $114 \mathrm{mNm}$ load. The PMSM driver is based on FCM8201. Although a position sensor with low resolution and simple algorithm has been used, the dynamic performance of PMSM is satisfactory and the phase currents are sinusoidal. These satisfactory results using low solution position sensors and simple driver prove that the proposed driver system can be used for applications such as solar pumps, conveyors, fans, small battery powered cars, medical applications and office machines.

\section{REFERENCES}

[1] Tae-Hyung Kim, M. Ehsani, "Sensorless control of the BLDC motors from near-zero to high speeds", IEEE Trans. Power Electronics, vol. 19, no. 6, pp. 1635-1645, 2004. [Online]. Available: http://dx.doi.org/10.1109/TPEL.2004.836625

[2] Ming-Shi Huang, Chin-Hao Chen, Hsin-Hung Chou, Guen-Zheng Chen, Wen-Ko Tsai, "An accurate torque control of permanent magnet brushless motor using low-resolution hall-effect sensors for light electric vehicle applications", IEEE Int. Conf. Electrical Machines, 2011, pp. 1-6.

[3] J. C. Gamazo-Real, E. Vazquez-Sanchez, J. Gomez-Gil, "Position and speed control of brushless DC motors using sensorless techniques and application trends", Sensors, vol. 10, pp. 6901-6947, 2010. [Online]. Available: http://dx.doi.org/10.3390/s100706901

[4] Shigeo Morimoto, Masayuki Sanada, Yoji Takeda, "Sinusoidal current drive system of permanent magnet synchronous motor with low position sensor", IEEE Industry Applications Conf., San Diego, CA., 1996, pp. 9-14. [Online]. Available: http://dx.doi.org/10.1109/ ias. 1996.556990

[5] K. A. Corzine, S. D. Sudhoff, "A hybrid observer for high performance brushless DC motor drives", IEEE Trans. Energy Conversion, vol. 11, no. 2, pp. 318-323, 1996. [Online]. Available: http://dx.doi.org/10.1109/60.507184

[6] J. Bu, L. Xu, T. Sebastian, B. Liu, "Near-Zero speed performance enhancement of PM synchronous machines assisted by low cost halleffect sensors," in Proc. IEEE Appl. Power Electron. Conf. (APEC) Anaheim, CA, 1998, pp. 68-74.

[7] J. X. Shen, Z. Q. Zhu, D. Howe, "PM brushless drives with Low Cost and Low resolution Position sensors", in Proc. Int. Power Electron. Motion Control Conf. (IPEMC), Wian, China, vol. 2, 2004, pp. 1033 1038 .

[8] F. G. Capponi, G. De Donato, L. Del Ferraro, O. Honorati, M. C. Harke, R. D. Lorenz, "AC brushless drive with low-resolution halleffect sensors for surface moynted PM machines", IEEE Trans Industrial Applications, vol. 42, no. 2, pp. 526-535, 2006. [Online]. Available: http://dx.doi.org/10.1109/TIA.2005.863904

[9] S. Y. Kim, C. Choi, K. Lee, W. Lee, "An improved rotor position estimation with vector-tracking observer in PMSM drives with lowresolution hall-effect sensors", IEEE Trans. Industrial Electronics, vol. 58, no. 9, pp. 4078-4086, 2011. [Online]. Available: http://dx.doi.org/10.1109/TIE.2010.2098367

[10] T. D. Batzel, K. Y. Lee, "Slotless permanent magnet synchronous motor operation without a high resolution rotor angle sensor", IEEE Trans. Energy Conversion, vol. 15, no. 4, pp. 366-377, 2000. [Online]. Available: http://dx.doi.org/10.1109/60.900494

[11] A. Yoo, S. Ki Sul, D. C. Lee, C. S. Jun, "Novel speed and rotor position estimation strategy using a dual observer for low-resolution position sensors", IEEE Trans. Power Electronics, vol. 24, no. 12, pp. 2897-2906, 2009. [Online]. Available: http://dx.doi.org/10.1109/ TPEL.2009.2022969

[12] OMRON Electronic Components LLC. "Photomicrosensor (Transmissive) EE-SX1041".

[13] Fairchild Semiconductor Corporation, "FCM8201 3-Phase Sinusoidal Brushless DC Motor Controller", 2011.

[14] G. Bal, M. Cihat Ozgenel, S. Demirbas, "Dynamic analysis of vector controlled permanent magnet synchronous motor driven with SPWM inverter", J. Fac. Eng. Arch. Gazi Univ., vol. 25, no. 3, pp. 569-577, 2010.

[15] W. A. Salah, D. Ishak, K. J. Hammadi, "PWM switching strategy for torque ripple minimization in BLDC motor", Journal of Electrical Engineering, vol. 62, no. 3, pp. 141-146, 2011. http://dx.doi.org/ 10.2478/v10187-011-0023-1 